\title{
PERANCANGAN MASTER DATA MANAGEMENT PADA REGULATOR INSTITUSI FINANSIAL
}

\author{
Sugiarto Hartono \\ Program Sistem Informasi, Program Studi Sistem Informasi, Universitas Bina Nusantara \\ Jln. K.H. Syahdan No. 9, Palmerah, Jakarta Barat, 11480 \\ Telp. (021) 5345830 \\ E-mail: shartono@binus.edu
}

\begin{abstract}
ABSTRAKSI
Regulator Institusi Finansial di Indonesia mengemban amanat dan wewenang untuk menyelenggarakan sistem pengaturan dan pengawasan yang terintegrasi terhadap keseluruhan kegiatan di pelaku Industri Jasa Keuangan (IJK). Tujuan penelitian ini adalah untuk menghasilkan single view data Akuntan dan Penilai, untuk melakukan migrasi data Akuntan dan Penilai yang ada pada excel ke sistem, dan dapat dijadikan pondasi dan langkah awal dalam penerapan MDM untuk sektor lainnya di Regulator Institusi Finansial. Metode yang digunakan dalam penelitian ini adalah studi literatur, studi lapangan (wawancara dan dokumentasi), serta menggunakan Object Oriented Analysis and Design. Solusi yang diberikan adalah dengan melakukan perancangan master data management agar tidak terjadi kesalahan serta mempercepat dalam pengambilan keputusan (dalam hal redudansi data pada profesi penunjang lainnya) dikarenakan media penyimpanan data masing masing profesi berbeda.
\end{abstract}

Kata Kunci: Object Oriented Analysis and Design, Master Data Management, Perancangan Sistem 


\section{PENDAHULUAN}

Semenjak berdirinya pada tahun 2011, Regulator Institusi Finansial di Indonesia mengemban amanat dan wewenang untuk menyelenggarakan sistem pengaturan dan pengawasan yang terintegrasi terhadap keseluruhan kegiatan di pelaku Industri Jasa Keuangan (IJK). Adapun IJK yang dikelola dapat diklasifikasikan menjadi tiga kompartemen, yaitu: Perbankan, Pasar Modal (PM) dan Industri Keuangan Non-Bank (IKNB). Amanat dan kewenangan tersebut didukung dengan keberadaan beberapa Sistem Informasi Bisnis Utama dan Pendukung. Namun sistem informasi tersebut masih dikelola secara terpisah (silo-based) berdasarkan jenis kompartemen/ sektor. Dengan adanya beragam sistem informasi yang berjalan, hal ini menimbulkan adanya overlapping system. Karena didalam setiap sistem terdapat pendefinisian berulang data yang bersifat umum (common data). Tentu hal ini berdampak tidak efisiennya IT Governance didalam proses penggunaan data dari sistem informasi yang saling terkait sehingga berdampak pada tidak optimalnya pemanfaatan fungsi bisnis.

Untuk dapat menyelenggarakan pengawasan konglomerasi secara komprehensif maka dibutuhkan tata kelola data yang efisien dan efektif, oleh karena itu dibuatlah Analisis dan Desain Master Data Management (MDM). Dalam hal memaksimalkan akses dan kualitas pemanfaatan data master Pelaku IJK, MDM dapat menghasilkan single version of thruth (satu versi tunggal terpercaya) seperti yang telah dipaparkan oleh Dreibelbis et al (2008). Tujuan akhir dari MDM adalah dapat mengefisiensikan operasional dan keakuratan analisis data.

Dalam rangka mewujudkan implementasi Master Data Management secara menyeluruh pada Regulator Institusi Finansial, maka dibutuhkan roadmap penerapan Master Data Management secara bertahap. Data Akuntan dan Penilai dinilai dapat menjadi piloting project dalam penerapan Master Data Management di Regulator Institusi Finansial, mengingat pengolahan data masih menggunakan excel dan adanya kebutuhan data profil yang akurat dan terpercaya untuk mendukung fungsi pengawasan pada Direktorat Lembaga dan Penunjang Pasar Modal (DLPM). Di samping itu banyak ditemukan data pokok Akuntan dan Penilai yang tidak lengkap dan data duplikasi sehingga berdampak pada fungsi pengawasan di DLPM. Untuk melakukan proses cleansing data diperlukan adanya pengecekan dan konfirmasi keakuratan data sehingga dapat dikatakan akurat dan terpercaya.

Dengan adanya piloting project ini diharapkan dapat menjadi pondasi bagi penerapan MDM kedepannya. Karena untuk mewujudkan terselenggaranya pengawasan terintegrasi yang komprehensif sebagaimana telah dijelaskan di atas diperlukan single version of thruth dari seluruh data pelaku Industri Jasa Keuangan pada masing-masing sektor di Regulator Institusi Finansial.

\section{METODE PENELITIAN}

Metodologi penelitian terbagi ke dalam 3 tahap, antara lain:

1. Metode Studi Literatur

Tahap studi literatur digunakan untuk memahami proses yang sedang berlangsung, yaitu dengan cara mendokumentasikan data dan informasi yang ada pada legacy system untuk memberikan dasar dalam analisis dan desain master data management untuk data Akuntan dan Penilai di Regulator Institusi Finansial.

\section{Metode Pengumpulan Data}

Metode pengumpulan data dapat dilakukan dengan cara - cara berikut:

- Mengambil data dari company profile.

- Studi lapangan, melakukan survei secara langsung terhadap sistem yang sedang berjalan.

\section{Metode Analisis dan Desain}

Dalam melakukan penyusunan scripsi ini, metode yang digunakan adalah Object Oriented Analysis and Design (OOAD) dengan notasi Unified Modelling Language (UML), (Satzinger, Jackson, Burd, 2012).

\section{HASIL DAN DISKUSI}

Regulator Finansial Institusi adalah lembaga negara yang dibentuk berdasarkan UU nomor 21 tahun 2011 yang berfungsi menyelenggarakan sistem pengaturan dan pengawasan yang terintegrasi terhadap keseluruhan kegiatan di dalam sektor jasa keuangan.

Regulator Institus Finansial adalah lembaga yang independen dan bebas dari campur tangan pihak lain, yang mempunyai fungsi, tugas, dan wewenang pengaturan, pengawasan, pemeriksaan, dan penyidikan.

Regulator Institusi Finansial mempunyai fungsi menyelenggarakan sistem pengaturan dan pengawasan yang terintegrasi terhadap keseluruhan kegiatan di sektor jasa keuangan.

Dalam menjalankan proses bisnis yang sedang berjalan, masih terdapat unit kerja yang menjalankan proses bisnisnya secara manual salah satunya yaitu pada Direktorat Lembaga dan Profesi Penunjang Pasar Modal (DLPM).

DLPM sendiri mengawasi 5 (lima) lembaga penunjang dan 4 (empat) profesi penunjang Pasar Modal diantaranya adalah:

a. Lembaga Lembaga Penunjang

a) Bank Kustodian 
b) Biro Administrasi Efek

c) Wali Amanat

d) Pemeringkat Efek

b. Profesi Penunjang

a) Akuntan

b) Konsultan Hukum

c) Penilai

d) Notaris

e) Profesi Lain

Pada Direktorat Lembaga dan Penunjang Pasar Modal (DLPM) saat ini, data Akuntan dan Penilai yang ada terbagi kedalam dua media penyimpanan yaitu pada aplikasi berbasis web yaitu portal.ojk.go.id dan pada excel. Portal.ojk.go.id sebelumnya digunakan untuk mengelola dan menyimpan data lembaga dan profesi penunjang Pasar Modal. Namun, portal.ojk.go.id tidak dapat lagi digunakan karena keterbatasan fitur seperti tidak dapat menambahkan data karena tidak tersedia pilihan tahun 2014 sampai dengan 2017. Untuk itu, data dari tahun 2014 sampai sekarang disimpan pada excel.

Untuk melengkapi data Akuntan dan Penilai, DLPM men-generate data yang ada pada portal.ojk.go.id kemudian memindahkannya kedokumen excel. Selanjutnya, penambahan dan update data dilakukan pada dokumen excel tersebut.

Pengawasan secara umum dapat dinilai efektif atau tidak efektif melalui dua indikator penting, yaitu optimal atau tidak optimalnya pengawasan yang dilakukan oleh sebuah regulator terhadap para pelaku, serta komitmen lembaga penunjang dalam menjalankan fungsi masing-masing secara profesional.

Dalam melakukan pengumpulan data dilakukan beberapa kali pertemuan untuk mendapatkan data yang diinginkan.

Proses identifikasi dari pengumpulan data yang di lakukan di DLPM dapat disimpulkan bahwa:

\section{a. Data belum memiliki standar}

Karena setiap pelaksana kegiatan operasional baik Akuntan maupun Penilai mengelola data dan informasi sendiri, maka setiap unit akan menyusun standar dan metode terhadap data dan informasi yang di kelola. Sehingga, setiap unit dalam kegiatan operasinalnya mempunyai entitas data sendiri terhadap entitas yang sama. Sehingga satu entitas memiliki identitas yang beragam.

\section{b. Data Inkonsisten}

Data inkonsisten terjadi akibat kondisi ketidaktahuan unit pelaksana akan data yang sama pada unit pelaksanaan yang lain sebagai akibat dari pemakaian data secara terpisah dan intrepretasi terpisah, sehingga data seperti di isolasi. Isolasi data juga menyebabkan sulitnya untuk mengakses data dalam unit kerja yang berbeda, padahal kebutuhan untuk mengakses data dari unit kerja lain. c. Tidak ada data history

Tanpa tata kelola data, proses koordinasi data dan informasi pada setiap levelnya, di anggap tidak penting.

d. Tidak di ketahui data yang paling mutakhir untuk di jadikan acuan

Hal ini terjadi akibat kesalahan interpretasi dari sebuah proses bisnis yang hasilkan dari unit pelaksana kegiatan operasional yang berbeda. Hal ini mengakibatkan data menjadi redudan (disimpan berkali-kali).

Sehingga perlu dilakukan langkah-langkah sebagai berikut :

a. Menyusun Standard Penulisan Data

Untuk mendapatkan data yang berkualitas, maka proses mendapatkan data tersebut haruslah mudah tanpa perlu melakukan prosedur manual, sehingga dapat menghemat waktu normal kerja.

b. Untuk mengendalikan dan mengontrol penggunaan Master Data Manajemen ini, maka akan di susun manajemen data yang terdiri dari struktur organisasi dan fungsi dari setiap pengguna di sebut juga dengan data governance.

Berdasarkan hasil requirement dengan pengguna, maka standard penulisan data yang dibutuhkan sesuai dengan Regulator dan nomenklatur adalah sebagai berikut:

A. Penulisan Nama Orang

Penulisan nama akan diformat sebagai berikut:

1. Nama Depan

2. Nama Tengah

3. Nama Belakang

4. Gelar (Dapat ditambahkan lebih dari satu)

Untuk menampilkan data sebagai"Display Name", maka data akan di tulis dengan nomenclature sebagai berikut :

a. Awal kata di tulis dengan huruf besar, contohnya :Anindia Islahudin

b. Untuk personal status, penulisan batasi dengan menggunakan dengan tanda "titik" dan dipisah dengan spasi, contohnya : Ny. Anindia Islahudin

c. Penulisan gelar dipisah dengan tanda "koma", contohnya Ny. Anindia Islahudin, Akt

\section{B. Penulisan Alamat Tempat Tinggal}

Tempat tinggal atau biasa dikenal sebagai alamat rumah, di tulis dengan format sebagai berikut :

a. Nama Gedung/Nama Kompleks Perumahan

b. Nama Jalan :

c. RT/RW

d. Kelurahan

e. Kecamatan

f. Kotamadya/Kabupaten

g. Negara

h. Kode Pos 
Untuk menampilkan data sebagai "Display Address", maka data akan di tulis dengan nomenclature sebagai berikut :

Awal kata di tulis dengan huruf besar, contohnya:Kompleks Bukit Indah

Untuk menuliskan pemisahan antara satu keterangan dengan keterangan lainnya, penulisan batasi dengan menggunakan dengan tanda "Spasi" dan dipisah dengan spasi. Contohnya :

Kompleks Bukit Indah No 31 RT.05/RW.08 Kelurahan Bekasi Utara Bekasi Jawa Barat

\section{Penulisan Alamat Kantor}

Penulisan alamat kantor dilakukan dengan format sebagai berikut :
a. Nama Gedung/Nama Kompleks Perumahan
b. RT/RW
c. Kelurahan
d. Kecamatan
e. Kotamadya/Kabupaten
f. Negara
g. Kode Pos

Untuk menampilkan data sebagai "Display Address", maka data akan di tulis dengan nomenclature sebagai berikut :

a. Awal kata di tulis dengan huruf besar, contohnya : Kompleks Perkantoran Golden Truly

Untuk menuliskan pemisahan antara satu keterangan dengan keterangan lainnya, penulisan batasi dengan menggunakan dengan tanda "Spasi" dan dipisah denganspasi . Contohnya :

Kompleks Perkantoran Golden Truly No31 RT.05/RW.08 Jalan Bantar Utara Kelurahan Bekasi Utara Bekasi Jawa Barat

D. Penulisan Nama Kantor

a. Nama Satu

b. Nama Dua

c. Tanda Penghubung " $\&$ "

d. Nama ke 3

Penulisan nama kantor misalnya untuk akuntan publik, notaris dan konsultan hukum dapat ditulis sesuai dengan nomenclature sebagai berikut:

a. Diawali dengan huruf besar

b. Nama Orang dipisahkan dengan tanda "\&", contohnya : Salam Rauf, Syarbini \& Rekan

E. Penulisan Nomor SSTD

Penulisan Nomor STTD dapat ditulis sebagai berikut :
a. Nomor Urut Perizinan
b. Dipisahkan dengan garis miring “/”
c. Identitas Organisasi
d. Nama Perizinan
e. Jenis Perizinan
f. Tahun Perizinan

Dalam Nomenclatur dapat ditulis sebagai berikut :

a. Identitas organisasi ditulis lengkap b. Nama perizinan di tulis sesuai kode yang di nomenclaturkan

c. Tahun ditulis dengan huruf latin. Contohnya :88/Bapepam-LK/SSTD-P/A-2009

F. Penulisan Tanggal

Format Penulisan tanggal mengikuti aturan internasional yang berlaku yaitu : $\mathrm{dd} / \mathrm{mm} /$ year. Contohnya, 20/01/2009.

G. Penulisan Nomor Telpon

Penulisan nomor telpon di dahului dengan :

a. Kode Negara

b. Kode Area

c. No Telp

Contohnya: +62218297876

Operasional Data dalam prinsip DAMA adalah petugas yang ditunjuk untuk melakukan proses pemutatkhiran data, mulai dari proses input data, koreksi, persetujuan dan approval. Dalam proses ini yang menentukan pekerjaan dari setiap operator terhadap data.

Single view data sangat dibutuhkan dalam peranan sistem informasi terintegrasi, "single view" dan "single version of truth" hanya dapat dicapai dengan menggunakan satu kerangka kerja yang jelas dan terkendali. Kompleksitas data tentu membuat tujuan itu sulit direalisasikan, maka dari itu perlu adanya master data untuk mengelola berbagai data sehingga terintegrasi.

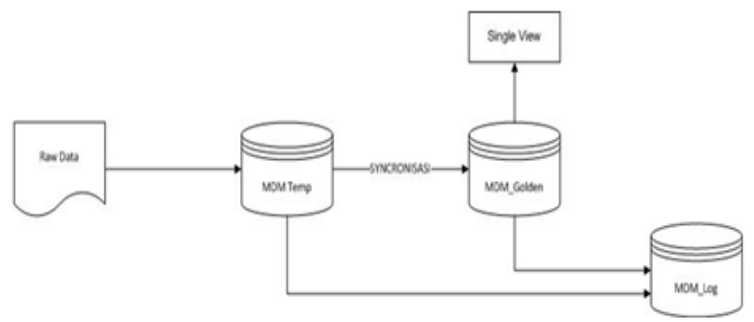

Gambar 1. Arsitektur Proses untuk mendapatkan MDM_GOLDEN

Berikut Use case diagram yang dirancang untuk proses bisnis usulan dari Master Data Management. 


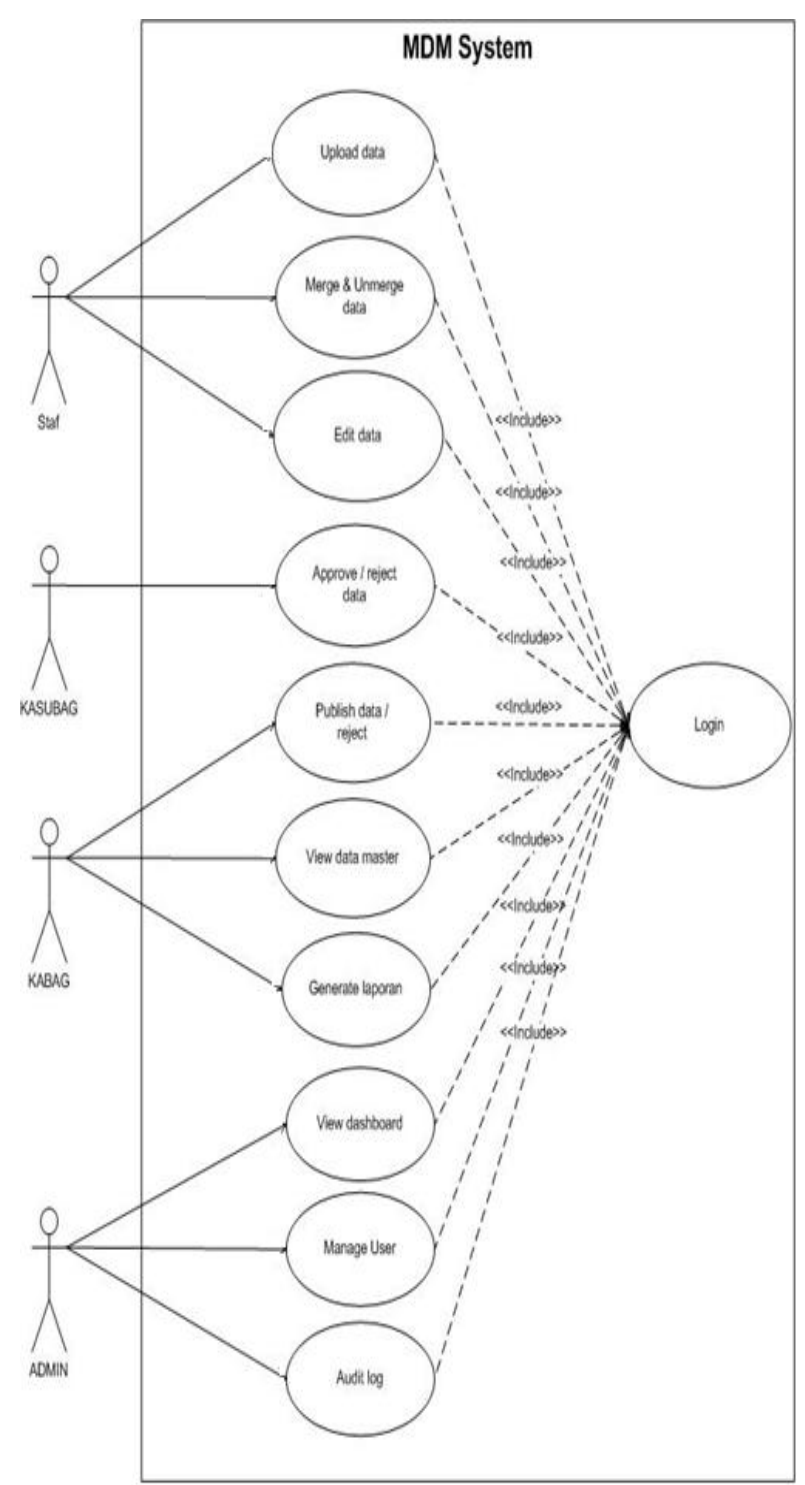

Gambar 2. Use Case Diagram

Berikut class diagram dari sistem usulan

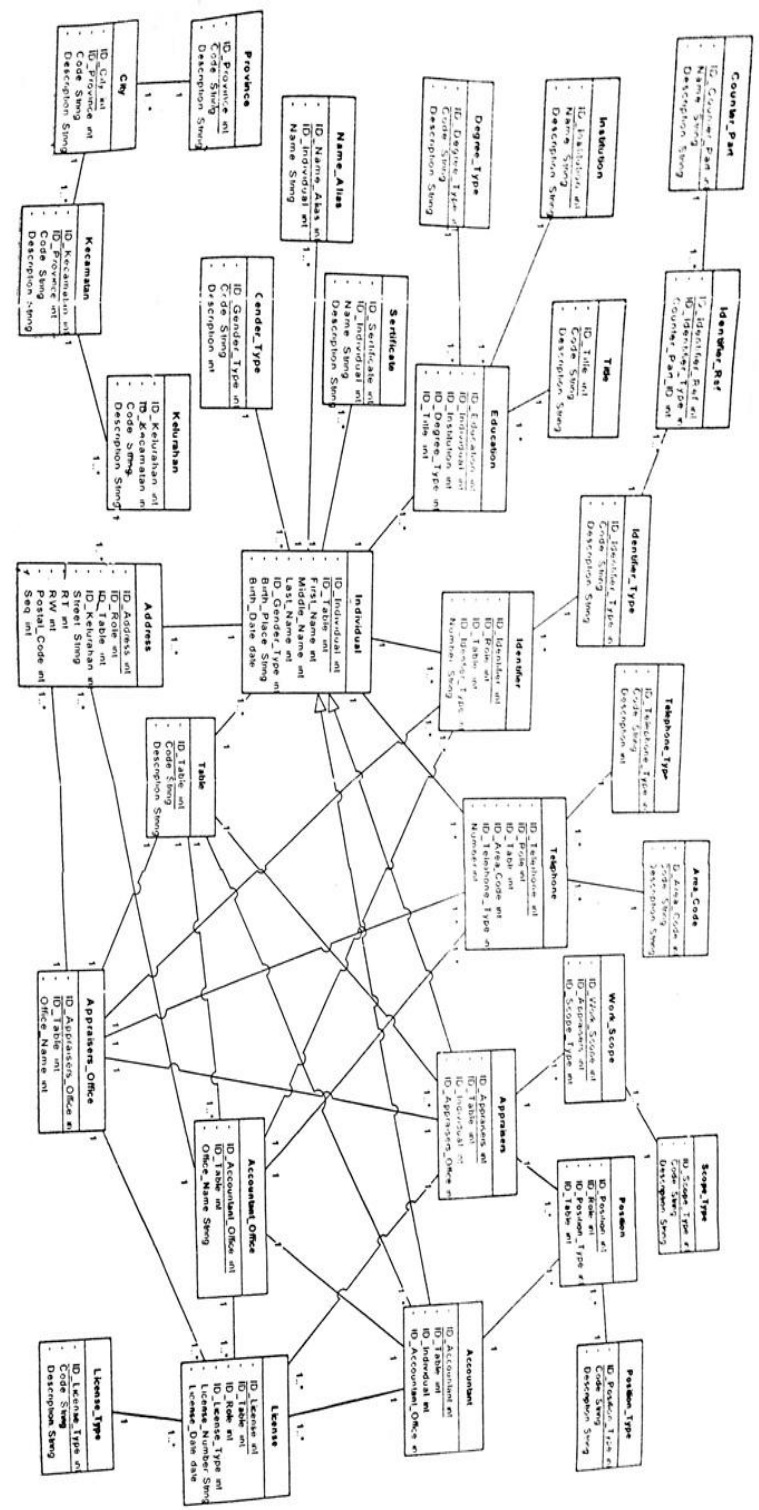

Gambar 3. Class Diagram

\section{KESIMPULAN}

Dari hasil analisis yang telah dilakukan, maka dapat disimpulkan beberapa hal terkait dengan adaya identifikasi masalah adalah sebagai berikut:

1. Penyimpanan data Akuntan dan Penilai masih di dalam excel, untuk itu pada aplikasi MDM disediakan tombol upload untuk memindahkan semua data dari excel ke sistem untuk dapat diolah di MDM System.

2. Adanya data Akuntan dan Penilai yang tidak lengkap. Dengan adanya MDM, data Akuntan dan Penilai akan dianalisis dan diperiksa kebenarannya sehingga tidak lagi terdapat data yang tidak lengkap maupun data duplikat.

3. Level pengecekan keakuratan dan kebersihan data Akuntan dan Penilai masih pada level Staf. Untuk itu pada MDM dibuat tahapan approval data 
dimana hasil kerja staf ada penanggung jawabnya agar data yang dihasilkan benar benar terjamin.

\section{DAFTAR PUSTAKA}

Al-Bahra bin Ladjamudin. (2005). Analisis dan Desain Sistem Informasi. Yogyakarta : Graha Ilmu.

Berson, A., \& Dubov, L. (2007). Master Data Management and Customer Data Integration for a Global Enterprise. McGraw-Hill Education.
Gonzales, M. L., 2003, IBM Data Warehousing with IBM Bussiness Intelligence Tools, Wiley Publishing Inc., Indiana.

O'Brien, J.A dan Marakas, G.M. 2008. Introduction to Information Systems. McGraw-Hill/Irwin.

Satzinger, J. W., Jackson, R. B., \& Burd, S. D. (2009). System Analysis And Design In A Changing World. USA: Course Technology

Satzinger, J. W., Jackson, R. B., \& Burd, S. D. (2012). System Analysis And Design In A Changing World. USA: Course Technology 